\title{
PENGARUH PEMANFAATAN MOBILE INSTANT MESSAGING (MIM) PADA PEMBELAJARAN MATERI HUKUM NEWTON TERHADAP KEMAMPUAN BERPIKIR TINGKAT TINGGI
}

\author{
Sholihatin ${ }^{1}$, Wayan Suana ${ }^{2}$, Feriansyah Sesunan ${ }^{3}$ \\ 1,2,3 Universitas Lampung \\ e-mail: wsuane@gmail.com
}

\begin{abstract}
This study aims to determine the effect of using Mobile Instant Messaging (MIM) on learning the material of Newton's Law on higher order thinking skills. MIM in the form of WhatsApp is used as a treatment in collaborative learning. The research method used pre-experimental design with the design of one group pretest posttest. This research was conducted at Kebumen Tanggamus Islamic High School in the odd semester of the 2018/2019 academic year. The population is all class X MIA with a total of 91 students. The research sample used was class X MLA 1 and class X MIA 3 as the experimental class with a total 53 students. The data analysis technique used is the calculation of the N-gain value. The results showed that the use of MIM in the form of a Whats App application on learning material in Newton's Law had an effect on the ability to think highly as seen from the results of the calculation of the $n$-gain value. The highest n-gain value on the C4 indicator is 0.69 while the C5 indicator is 0.32 and the C6 indicator is 0.36 with an average ngain value of 0.41 which is included in the medium category.
\end{abstract}

Keywords: Mobile Instant Messaging, WhatsApp, Higher Order Thinking Skill (HOTS)

\begin{abstract}
Abstrak: Penelitian ini bertujuan untuk mengetahui pengaruh pemanfaatan Mobile Instant Messaging (MIM) pada pembelajaran materi Hukum Newton terhadap kemampuan berpikir tingkat tinggi. MIM berupa aplikasi Whats $A p p$ digunakan sebagai media dalam pembelajaran kolaboratif (gabungan tatap muka di kelas dengan aktivitas online). Metode penelitian menggunakan pre experimental design dengan desain one group pretest posttest. Penelitian ini dilakukan di SMA Islam Kebumen Tanggamus pada semester ganjil tahun ajaran 2018/2019. Populasinya yaitu seluruh kelas X MIA yang berjumlah 91 peserta didik. Sampel penelitian yang digunakan adalah kelas X MIA 1 dan kelas X MIA 3 sebagai kelas eksperimen dengan jumlah 53 peserta didik. Teknik analisis data yang digunakan adalah perhitungan nilai $n$-gain. Hasil penelitian menunjukkan bahwa pemanfaatan MIM berupa Whats App pada pembelajaran materi Hukum Newton berpengaruh terhadap kemampuan berpikir tinggi yang dilihat dari hasil perhitungan nilai n-gain. Nilai n-gain tertinggi pada indikator $\mathrm{C}_{4}$ sebesar 0,69 sedangkan indikator $\mathrm{C}_{5}$ sebesar 0,32 dan indikator $\mathrm{C}_{6}$ sebesar 0,36 dengan rata-rata nilai $n$-gain total sebesar 0,41 yang termasuk dalam kategori sedang.
\end{abstract}

Kata kunci: Mobile Instant Messaging, Whats App, Kemampuan Berpikir Tingkat Tinggi 


\section{PENDAHULUAN}

Kemampuan berpikir tingkat tinggi merupakan kemampuan yang penting dimiliki di abad 21 dan perlu diajarkan kepada peserta didik. Hal ini sejalan dengan pendapat Greenhill (2010) yang menyatakan "Teaching critical thinking in schools is one of the main topics in the discussion regarding so-called $21^{15}$ Century skills", pada pembelajaran abad ke-21 kemampuan peserta didik untuk berpikir tingkat tinggi menjadi tuntutan. Berdasarkan tes Programme Internationale for Student Assesment (PISA) tahun 2015, pendidikan di Indonesia menduduki ranking 69 dari 76 negara yang mengikuti tes PISA. Data yang dihasilkan dari tes PISA menunjukkan bahwa pentingnya guru mengarahkan peserta didiknya untuk berpikir tingkat tinggi (Julianingsih dkk., 2017). Data tes PISA 2015 tersebut menunjukkan bahwa kurang terlatihnya peserta didik Indonesia dalam menyelesaikan soal-soal yang termasuk dalam kategori soal-soal berpikir tingkat tinggi (Dewi \& Riandi 2016).

Sementara itu, pada abad 21 perkembangan Teknologi Informasi dan Komunikasi (TIK) sangatlah pesat. Pemanfaatan TIK seperti media sosial dan internet telah menyebar ke segala aspek kehidupan termasuk aspek pendidikan. Salah satu media sosial yang paling popular dan banyak digunakan yaitu Mobile Instant Messaging (MIM) berupa WhatsApp. Banyak kajian yang telah dilakukan yang menunjukkan kelebihan aplikasi MIM dalam memupuk pengetahuan dan meningkatkan interaksi sosial secara tidak langsung (Rambe \& Chipunza, 2013 ; Rambe \& Bere 2013). Survei yang dilakukan oleh Irwandani (2016) hampir 98\% peserta didik memiliki akun sosial media seperti Facebook, WhatsApp dan Instagram serta 94\% peserta didik menggunakan internet untuk mengerjakan tugas sekolahnya, platform berupa Whats App dapat menjadi salah satu pilihan untuk mempermudah proses pembelajaran kolaboratif. Zebua (2017) juga mengungkapkan bahwa 97,24\% responden survei menyatakan pernah menggunakan Whatss App dan 61,81\% menyatakan bahwa Whats App merupakan aplikasi instant messaging yang paling sering mereka gunakan.

Situs jejaringan media sosial sangatlah populer, media sosial tersebut memungkinkan anggota berinteraksi satu sama lain. Hal ini dikarenakan WhatsApp memiliki berbagai fitur yang dapat digunakan oleh guru dan peserta didik untuk berinteraksi serta berdiskusi dimanapun dan kapanpun Nasrullah (2015: 40). Tersedianya teknologi online yang mampu mendukung pengimplementasian prinsip-prinsip kontruktivisme, menjadikan teori belajar kontruktivisme semakin tepat sebagai landasan pembelajaran secara online (Muclas, 2016). Penelitian terkait Whats App diungkapkan oleh Naidoo dan Kopung (2016) bahwa sumber belajar Whats $A p p$ menyediakan kesempatan bagi guru pre-service untuk terlibat dalam interaksi 
yang bermakna. Selain itu, mereka juga berpendapat mampu mendorong peserta didik untuk aktif dan kolaboratif dalam belajar, menumbuhkan lingkungan belajar konstruktivis sosial. Manfaat penggunaan aplikasi Whats App dalam pembelajaran menurut Indaryani (2018) bahwa group Whats App memberikan fasilitas pembelajaran secara kolaboratif dan secara online antara guru dan peserta didik maupun sesama peserta didik baik di rumah maupun di sekolah untuk berbagi (komentar, tulisan, gambar, video, suara, dan dokumen), kemudahan untuk menyebarluasakan pengumuman maupun mempublikasikan karyanya dalam group Informasi dan pengetahuan dapat dengan mudah dibuat dan disebarluaskan melalui berbagai fitur Whats App.

Hasil angket kebutuhan peserta didik pada kelas X MIA 1 dan X MIA 3 di SMA Islam Kebumen menunjukkan bahwa 90\% dari peserta didik menggunakan internet untuk menyelesaikan tugas-tugas sekolahnya dan peserta didik juga memiliki smartphone. Kendala yang sering dihadapi guru dalam proses pembelajaran fisika yaitu masalah keterbatasan waktu, karena dalam menyampaikan pembelajaran fisika tidak hanya dengan membahas teori melainkan juga harus diiringi dengan adanya ekperimen. Hal ini tentu akan mempengaruhi tingkat pemahaman peserta didik dan menyebabkan tujuan pembelajaran yang ingin dicapai tidak terpenuhi secara menyeluruh.

Menurut Pratama dan Yusro (2016), bahwa implementasi WhatsApp sebagai mobile learning dapat meningkatkan hasil belajar peserta didik. Pembelajaran yang terintegrasi menggunakan MIM berupa WhatsApp Messenger memberikan manfaat pada peserta didik diantaranya yaitu: (1) informasi dan pengetahuan secara cepat dan mudah ditransfer, (2) kemudahan membuat forum diskusi sehingga media sosial menjadi sarana positif untuk belajar, (3) memfasilitasi kolaborasi tanpa batas antara pendidik dan peserta didik, (4) aplikasi gratis yang mudah digunakan. Sementara itu, Amalia dkk. (2017) mengemukakan bahwa aplikasi Whats $A p p$ memiliki kemampuan dalam memberikan respons time yang layak yaitu dengan menjembatani komunikasi antara penggunanya melalui diskusi ataupun berbagi gambar atau dokumen kapanpun dan dimanapun, sehingga hal inilah yang menjadikan aplikasi Whats App memiliki usability yang tinggi dan dapat digunakan dalam mendukung kegiatan pembelajaran di dalam kelas ataupun di luar kelas.

Pembelajaran berorientasi pada kemampuan berpikir tingkat tinggi perlu diterapkan oleh guru dalam melatihkan kemampuan berpikir tingkat tinggi. Pemanfaatannya grup Whats $A p p$ digunakan sebagai treatment melatihkan HOTS dalam kegiatan diskusi, klarifikasi, evaluasi ide dan gagasan sebagai upaya untuk melatihkan keterampilan kolaborasi dan refleksi yang merupakan autentic learning. Berdasarkan pemaparan masalah dan potensi Whats App yang telah 
diuraikan, bahwa terdapat beberapa penelitian yang mengimplementasikan Whats App dalam pembelajaran. Peneliti telah melakukan penelitian serupa tentang bagaimana pengaruh pemanfaatan Mobile Instant Messaging berupa WhatsApp pada pembelajaran materi Hukum Newton tentang gerak terhadap kemampuan berpikir tingkat tinggi peserta didik.

\section{METODE}

Penelitian eksperimen ini menggunakann pre experimental design dengan bentuk one group pre test post test. Desain penelitian ini melibatkan dua kelas yaitu kelas eskperimen dimana kedua kelas sama-sama diberikan perlakuan (treatment). Kelas eksperimen pada penelitian ini mendapatkan treatment pembelajaran colaboratif learning yaitu pembelajaran gabungan tatap muka dengan serangkaian aktivitas online di grub Whats $A p p$ serta dibantu Lembar Kerja Peserta Didik (LKPD) materi Hukum Newton tentang gerak yang dirancang untuk 3 kali pertemuan. LKPD tersebut menggunakan model blended learning yang berorintasi HOTS yang dikembangkan oleh Nuraini dkk. (2018). Kedua kelas eksperimen diberikan pre-test untuk mengetahui kemampuan awalnya. Hasil pre-test yang baik bila nilai kedua kelompok eksperimen tidak berbeda secara signifikan. Desain blended learning yang digunakan menurut Suana dkk. (2017) yaitu online learning - tatap muka - online learning.

Populasi penelitian ini adalah seluruh peserta didik kelas X MIA di SMA Islam Kebumen Tanggamus pada semester ganjil Tahun Ajaran 2018/2019 yang terdiri atas 4 (empat) kelas dengan jumlah 91 peserta didik. Teknik pengambilan sampel dilakukan secara purposive sampling. Sampel pada penelitian ini adalah dua kelas eksperimen kelas X MIA 1 dan kelas X MIA 3. Adapun instrumen yang digunakan dalam penelitian ini adalah intrumen yang sudah dikembangkan oleh Solekhah dkk. (2018). Instrumen tersebut diuji validitas dan reliabilitasnya sebelum digunakan. Instrumen berupa soal tes berbentuk pilihan jamak (multiple choice) yang beralasan sebanyak 20 butir soal dan digunakan untuk mengukur kemampuan berpikir tingkat tinggi peserta didik. Indikator tes kemampuan berpikir tingkat tinggi yang akan digunakan yaitu soal dengan indikator analisis $\left(\mathrm{C}_{4}\right)$, sintesis $\left(\mathrm{C}_{5}\right)$ dan mencipta $\left(\mathrm{C}_{6}\right)$. Instrumen tes ini digunakan pada saat kegiatan pre-test dan post-test dilakukan. Data yang diperoleh dalam penelitian ini adalah data kemampuan berpikir tingkat tinggi peserta didik baik secara keseluruhan maupun per indikatornya. Peningkatan kemampuan berpikir tingkat tinggi dapat dilihat setelah proses pembelajaran kolaboratif diberikan. Data yang diperoleh kemudian dianalisis dengan melakukan perhitungan nilai n-gain. Pengaruh treatment berupa aktivitas online dengan grup Whats App terhadap kemampuan berpikir tinhkat tinggi dilihat dari perhitungan nilai n-gain (Hake, 2002: 3). 
HASIL

Dari hasil penelitian diperoleh data kuantitatif ranah kognitif peserta didik pada hasil tes 20 butir soal pilihan jamak beralasan dengan indikator kemampuan berpikir tingkat tinggi yang dapat dilihat dari Tabel 1. sebagai berikut.

Tabel 1. Data Kuantitatif Hasil Penelitian

\begin{tabular}{llcc}
\hline \multirow{2}{*}{ No } & & \multicolumn{2}{c}{ Kelas Eksperimen } \\
\cline { 3 - 4 } & & Pretest & Posttest \\
\hline 1 & Jumlah peserta didik & 53 & 53 \\
\hline 2 & Nilai teredah & 20 & 42,5 \\
\hline 3 & Nilai tertinggi & 50 & 80 \\
\hline 4 & Rata-rata nilai & 27,9 & 58,9 \\
\hline 5 & Simpangan Baku & 8,39 & 8,64 \\
\hline
\end{tabular}

Berdasarkan Tabel 1. bahwa terdapat peningkatan skor nilai maksimum, nilai minimum, rata-rata dan simpangan baku dari pre-test ke post-test pada tes kemampuan berpikir tingkat tinggi. Perolehan data tersebut selanjutnya dihitung perolehan nilai n-gain total dan n-gain per indikatornya. n-gain digunakan untuk melihat perbedaan nilai pre-test dan post-test pada kedua kelas eksperimen yang kemudian dianalisis menggunakan skor gain ternormalisasi, sehingga dapat dilihat peningkatan kemampuan berpikir tingkat tinggi setelah diberikannya perlakuan berupa pembelajaran kolaboratif menggunakan MIM berupa diskusi grup Whats App. Perolehan rata-rata nilai $n$-gain total dan hasil gain maksimum dan minimun terdapat pada Tabel 2 . sebagai berikut.

Tabel 2. Perolehan skor gain dan N-gain

\begin{tabular}{lc}
\hline Perolehan $\mathbf{N}$-gain & Nilai \\
\hline gain Tertinggi & 45 \\
\hline gain Terendah & 7,5 \\
\hline$n$-gain Tertinggi & 0,69 \\
\hline$n$-gain Terendah & 0,13 \\
\hline Rata- rata n-gain & 0,41 \\
\hline Kategori & Sedang \\
\hline
\end{tabular}

Berdasarkan rata- rata perhitungan nilai n-gain yang disajikan dalam tabel menunjukkan bahwa bahwa pembelajaran kolaboratif memanfaatkan MIM untuk aktivitas online memiliki rata-rata $n$-gain dalam kategori sedang sebesar 0,41 dimana nilai $n$-gain pada rentang $0,3 \leq n$ gain $\leq 0,7$ dengan kategori peningkatan kemampuan berpikir tingkat tingginya adalah sedang. Perolehan skor rata- rata n-gain total dan n-gain per indikatornya terdapat pada Tabel 3. sebagai berikut. 
Tabel 3. Rata- rata N-gain per Indikator

\begin{tabular}{lc}
\hline Perolehan $\boldsymbol{n}$-gain per Indikator & Nilai \\
\hline Menganalisis $\left(\mathrm{C}_{4}\right)$ & 0,45 \\
\hline Mengevaluasi $\left(\mathrm{C}_{5}\right)$ & 0,32 \\
\hline Mencipta $\left(\mathrm{C}_{6}\right)$ & 0,36 \\
\hline
\end{tabular}

Nilai rata-rata $n$-gain setiap indikator dalam kemampuan berpikir tingkat tinggi baik itu kemampuan menganalisis $\left(\mathrm{C}_{4}\right)$, mengevaluasi $\left(\mathrm{C}_{5}\right)$ maupun kemampuan mencipta atau mengkreasi $\left(\mathrm{C}_{6}\right)$ termasuk kategori sedang. Perlakuan atau treatment berupa pemanfaatan MIM berupa aplikasi WhatsApp kedua kelas eksperimen mengalami peningkatan. Persebaran ratarata nilai $n$-gain kemampuan berpikir tingkat tinggi pada kedua kelas eksperimen atau kelas uji disajikan dalam Gambar 1. sebagai berikut.

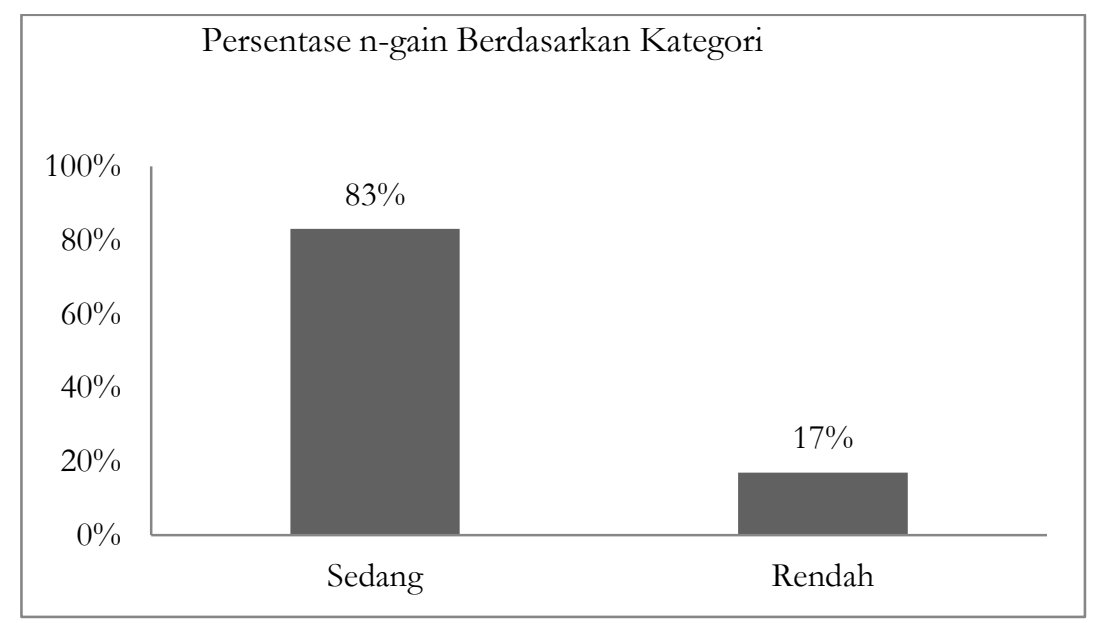

Gambar 1. Grafik Nilai n-gain dalam Kategori

Berdasarkan grafik bahwa $83 \%$ peserta didik pada kedua kelas eksperimen mengalami peningkatan kemampuan berpikir tingkat tinggi pada kategori sedang, sedangkan sisanya sebesar 17\% mengalami peningkatan kemampuan berpikir tingkat tinggi pada kategori rendah. Peserta didik yang aktif dalam aktivitas online cenderung memiliki peningatan gain yang lebih besar dibandingkan peserta didik yang pasif yang cenderung memiliki gain yang lebih kecil. 


\section{PEMBAHASAN}

Pemanfaatan MIM berupa aplikasi WhatsApp pada pembelajaran materi Hukum Newton tentang gerak berpengaruh terhadap kemampuan berpikir tingat tinggi, hal ini dapat diketahui melalui hasil perhitungan rata- rata nilai n-gain. Perhitungan nilai n-gain setiap indikator dalam kemampuan berpikir tingkat tinggi baik itu kemampuan menganalisis, mengevaluasi maupun kemampuan mencipta termasuk dalam kategori sedang. Nilai rata-rata n-gain yang paling tinggi peningkatanya adalah pada indikator kemampuan kognitif menganalisis $\left(\mathrm{C}_{4}\right)$ baik itu pengetahuan metakognitif, faktual maupun konseptualnya.

Peningkatan kemampuan berpikir tingkat tinggi peserta didik disebabkan karena adanya perlakuan atau treatment berupa serangkaian aktivitas online untuk kegiatan diskusi, klarifikasi, evaluasi ide dan gagasan. Peserta didik pada kedua kelas eksperimen menerapkan colaboratif learning dengan tambahan aktivitas online di WhatsApp dan kegiatan tatap muka di kelas yang merupakan bagian yang tidak dapat dipisahkan dalam suatu proses pembelajaran kolaboratif. Kegiatan dalam kelas online berupa tayangan fenomena maupun permasalahan dalam bentuk video maupun gambar yang erat dengan kehidupan sehari-hari peserta didik, sehingga membuat peserta didik tertarik dan penasaran untuk mengikuti kelas online dan menanggapi serta terlibat dalam kegiatan diskusi online. Pembelajaran kolaboratif gabungan online dan tatap muka memberikan kesempatan seluas-luasnya kepada peserta didik untuk menyampaikan ide dan gagasannya, kemudahan mendapatkan informasi dan materi penunjang pembelajaran sehingga pembelajaran tidak lagi berpusat pada guru melainkan pembelajaran berpusat pada peserta didik (student center) sesuai dengan tuntutan kurikulum 2013 saat ini. Peserta didik yang aktif berargumen dan sering menanggapi setiap fenomena dan permasalahan yang diberikan oleh guru cenderung memiliki peningkatan kemampuan berpikir tingkat tinggi lebih besar dibandingkan peserta didik yang pasif serta jarang muncul dalam grup.

Selain memberikan serangkaian aktivitas online pada pembelajaran kolaboratif, peserta didik juga tetap memperoleh pembelajaran tatap muka di kelas dengan metode eksperimen, tanya jawab, maupun kegiatan diskusi. Kegiatan pembelajaran tersebut dilakukan untuk melatihkan kemampuan berpikir tingkat tinggi peserta didik dalam hal menganalisis suatu fenomena maupun permasalahan, mengevalusi, maupun mencipta ide atau gagasan secara lebih efisien. Adapun penelitian yang relevan tentang penggunaan MIM diantaranya hasil penelitian Kartikawati dan Pratama (2017) tentang pengaruh WhatsApp Messenger sebagai Mobile Learning terintegrasi medote Group Investigation terhadap kemampun berpikir kritis 
menunjukkan bahwa ada peningkatan kemampuan berpikir secara mandiri dan kritis serta melatihkan peserta didik dalam menyelesaikan suatu permasalahan dalam kelompok belajar. Hal tersebut sesuai dengan pernyataan Susilo (2014) bahwa paradigma pendidikan terkait dengan proses pembelajaran bahwa saat ini proses pembelajaran tidak hanya menggunakan pertemuan tatap muka di dalam kelas saja, melainkan dapat dilakukan secara maya (online) lewat kehadiran teknologi internet. Hasil penelitian ini adalah temuan model kesiapan, keyakinan dan difusi layanan pesan teks singkat (instant messaging) pada tutorial online melalui pemanfaatan Whats $A p p$.

Kemampuan berpikir tingkat tinggi pada kedua kelas eksperimen yang memanfaatkan MIM berupa WhatsApp dalam pembelajaran kolaboratif belum memperoleh hasil yang memuaskan. Hal tersebut dikarenakan dalam pelaksanaannya terdapat kendala-kendala yang dihadapi saat penelitian. Kendala penelitian berupa akses internet yang dimiliki peserta didik kurang memadai saat dilakukannya diskusi online kemudian tidak semua anggota grup mengikuti sepenuhnya kegiatan diskusi dari awal hingga akhir penugasan. Kendala lain yang dihadapi adalah kurangnya pemahaman siswa tentang diskusi online karena sebelumnya belum pernah diterapkan dalam pembelajaran, adanya grup kelas hanya dipergunakan sebagai komunikasi antara wali kelas dengan anggota kelasnya. Kegiatan pertemuan dan pengajaran dalam penelitian ini juga sangat singkat yaitu selama tiga kali tatap muka dan tiga kali rangkain aktivitas online, oleh karena itu peningkatan kemampuan berpikir tingkat tinggi peserta didik masih dalam kategori sedang.

\section{PENUTUP}

Berdasarkan hasil penelitian maka diperoleh simpulan bahwa pemanfaatan Mobile Instant Messaging (MIM) berupa aplikasi Whats App pada pembelajaran materi Hukum Newton tentang gerak berpengaruh terhadap peningkatan kemampuan berpikir tingkat tinggi peserta didik. Hal tersebut dilihat dari perhitungan nilai n-gain, dimana nilai n-gain tertingginya pada indikator menganalisis $\left(\mathrm{C}_{4}\right)$, sedangkan rata-rata n-gain totalnya termasuk dalam kategori sedang.

Saran yang ingin disampaikan untuk peneliti lain yang akan melakukan penelitian serupa berdasarkan hasil penelitian yaitu sebelum melakukan penelitian pemanfaatan MIM dalam pembelajaran kolaboratif sebaiknya peneliti memberikan pengetahuan terlebih dahulu tentang cara, peraturan, serta manfaat yang akan diperoleh kepada peserta didik agar peserta didik lebih siap untuk mengikuti pembelajaran kolaboratif dan menganalisis juga pengaruh 
media lain serta faktor lain di luar platform MIM. Hasil penelitian yang telah diperoleh ini dapat dijadikan referensi dan bahan kajian untuk peneliti yang akan melakukan penelitian serupa terkait dengan pengaruh pemanfaatan MIM pada pembelajaran terhadap kemampuan berpikir tingkat tinggi agar diperoleh hasil penelitian yang lebih baik lagi.

\section{REFERENSI}

Amalia, F., Admaja, Herlambang dan Afirianto, T. (2017). Perbandingan system funcionaly, system interactivity dan usability pada Instant Messaging (IM) sebagai media pembelajaran sinkron. J. Pendidikan Teknologi Informasi Universitas Brawijaya, 7(1): 1 - 4.

Dewi, N. dan Riandi, R. (2016). Analisis kemampuan berpikir kompleks siswa melalui pembelajaran berbasis masalah berbantuan mind mapping. J. Education and Sains, 8 (1): 98 $-107$.

Greenhill, Valerie. (2010). 21st Century Knowledge and Skills in Educator Preparation. Washington: Partnership for 21st Century Skills.

Hake, R.R. (2002). Relationship of Individual Student Normalized Learning Gains in Mechanics with Gender, High-School Physics, and Pretest Scores on Mathematics and Spatial Visualization. Boise, Idaho: Physics Education Research Conference.

Hayati, I., \& Sujadi, E. (2018). Perbedaan Keterampilan Belajar Antara Siswa IPA dan IPS. Tarbawi : Jurnal Ilmu Pendidikan, 14(1), 1-10. doi:10.32939/tarbawi.v14i1.250

Indaryani, Eka dan Sulisworo, D. (2018). Dampak pemanfaatan Whatsapp dalam meningkatkan motivasi belajar pada materi fisika. Papers Seminar Nasioanal Quantum. 25-30.

Irwandani, S.J. (2016). Pengembangan media pembelajaran berupa komik fisika berbantuan media sosial instagram sebagai alternatif. J.Imiah Pendidikan Fisika, 5 (1): 33 - 42.

Julianingsih, S., Rosidin, U. \& Wahyudi, I. (2017). Pengembangan instrumen asesmen hots untuk mengukur dimensi pengetahuan IPA siswa di SMP. J. Pembelajaran Fisika, 3 (3): 59 $-66$.

Kartikawati, S. \& Hendrik, P. (2017). Pengaruh penggunaan whatsapp messengger terintegrasi metode group investigation terhadap kemampuan berpikir kritis. J. Pendidikan Teknik Eleketro, 2 (2): 33 - 38.

Muclas. (2016). Blended learning berbasis kontruktivisme untuk pembelajaran praktik di perguruan tinggi teknik. Seminar Nasional Vokasi dan Teknologi (SEMNASVOKTEK). $61-76 \mathrm{hlm}$.

Naidoo, J. \& Kopung, Kabelo J. (2016). Exploring the Use of WhatsApp in Mathtematics Learning: A Case Study. Journal Communication, 7 (2): 266-273.

Nasrullah, Rulli. (2015). Media Sosial. Bandung: Simbiosa Rekatama. 
Nuraini, S., Distrik, W. \& Suana, W. (2018). Pengembangan lembar kerja siswa blended learning berorientasi bigher order thinking skill. J. Physics and Science Learning, 2 (1): 69 - 77.

Rambe, P. dan Bere, A. (2013). Using mobile instant messaging to leverage learner participation and transform pedagogy at a south african university of technology. $J$. EducationalTechnology, 44 (4): 1 - 6.

Rambe, P. dan Chipunza, C. (2013). Using Devices to Leverage Student Access to Collaboratively Generated Resources: A Case of WhatsApp Instant Messaging at a Suoth African University. Internasional Conference on Advanced Information and Communication Technology for Education (ICAICTE 2013). 331-337 hlm.

Sholekhah, F.M., Maharta, N dan Suana, W. (2018). Pengembangan instrumen tes kemampuan berpikir tingkat tinggi pada materi hukum newton tentang gerak . J. Physics and Science Learning, 2 (1): 17 - 26.

Suana,W., Maharta, N., Nyeneng, I.D., \& Wahyuni, S. (2017). Desain and Implementation of Schoology Based Learning Media for Basic Physics I Course. J. Pendidikan IPA Indonesia, 6 (1).

Sujadi, E. (2017). Penerapan Pendidikan Karakter Cerdas Format Kelompok Untuk Meningkatkan Nilai Kejujuran Mahasiswa Bimbingan Konseling Islam (BKI) Institut Agama Islam Negeri (IAIN) Kerinci. Tarbawi : Jurnal Ilmu Pendidikan, 13(1), 97-108

Sulisworo, D., dan Agustin, S. P., (2017). Dampak pembelajaran e-learning terhadap motivasi pada pembelajaran fisika di sekolah kejuruan. J. Berkala Fisike Indonesia, 9 (1): $3-6$.

Susilo, Adhi. (2014). Using facebook and whatsapp to leverage learner participation and transform pedadogy at the open University of Indonesia. J. Pendidikan Terbuka dan Jarak Jauh, 15 (2): $63-80$.

Yazdi, Mohammad.(2012). E-learning sebagai media pembelajaran interaktif berbasis teknologi informasi. J. Ilmiah Foristek, 2 (1): 143 - 146.

Zebua, Ferdinand. (2017). Laporan Daily Social: Survey Instant Messaging 2017. (online) di https://dailysocial.id/post/laporan-dailysocial-survey-instant-messaging-2017/. Diakses pada 10 Oktober 2018. 